\title{
Study on Manufacturing of Recycled SiC Powder from Solar Wafering Sludge and Its Application
}

\author{
Young-Lim Lee,", Soon-Taek Jeong', and Sang-Jun Park' \\ 1 Department of Mechanical Engineering, Kongju National University, Cheonan, South Korea, 330-717 \\ 2 NSSS Division, Kepco E\&C, Gyeonggi, South Korea, 446-713 \\ \# Corresponding Author / E-mail: ylee@kongju.ac.kr, TEL: +82-41-521-9123, FAX: +82-41-555-9123
}

KEYWORDS: Recycled SiC, Solar wafering sludge, Heat sink, Thermal conductivity

\begin{abstract}
Slurry containing SiC powder and oil is used to cut ingots with a wire in a solar cell wafering process. The slurry, which is generally recycled due to its high price, produces a residue known as sludge during the recycling process. The sludge is mainly composed of $\mathrm{SiC}$, Si, and oil. This study proposed a method to remove Si and oil from sludge to obtain a high-purity SiC powder of approximately 98.5\% in an economically feasible manner. Additionally, this study utilized the recycled SiC powder to develop a porous SiC ceramic heat sink with thermal conductivity of about $10 \mathrm{~W} / \mathrm{mK}$ and showed that the heat sink can be used as an efficient apparatus to release heat of electronics.
\end{abstract}

\section{NOMENCLATURE}

\author{
$\mathrm{cp}=$ centipoise \\ $\mathrm{D}_{\mathrm{x}}=$ percentile particle size distribution \\ $\mathrm{h}=$ hour \\ wt $\%=$ weight percent
}

\section{Introduction}

In line with development of the photovoltaic industry, not only the polysilicon and ingot manufacturing industry but also a relevant process and parts industry has been emerging. ${ }^{1}$ For the solar cell wafering process, a slurry that includes $\mathrm{SiC}$ powder and oil is used to cut silicon ingots with a wire-sawing machine. ${ }^{2,3}$ In other words, when a wire, whose main component is $\mathrm{Fe}$, passes through the slurry and pushes the ingot at a constant pressure, the slurry is pushed onto the surface of the wire and the ingot is cut off by $\mathrm{SiC}$ particles inside the slurry. At this time, the process causes the formation of a slurry that consists of oil, $\mathrm{Si}$ of the ingot component and $\mathrm{SiC}$ powder of the cutting fluid. This slurry is normally recycled to be reused due to its high price. ${ }^{4}$

Fig. 1 illustrates the slurry recycling system intended to recycle the cutting fluid, $\mathrm{SiC}$, which is used for cutting the silicon ingot. In the system, waste separated after the second decanter is called sludge. Domestically, silicon ingot wafering is estimated to produce approximately 7000 tons of sludge monthly. Out of the produced sludge, a solid phase, except the oil of lubricating coolant, accounts for almost $50 \%$, with an amount of 3,500 tons. As other fine powder including cut off $\mathrm{Si}$ occupies about $20 \%$ of the solid phase, $\mathrm{SiC}$ byproduct actually amounts to about 2,800 tons, and out of this, approximately $85 \%$ can be recycled to be reused for the wafering process. Therefore, Sic materials of 420 tons are disposed of as waste monthly and 5,040 tons annually, which is equal to disposal of USD

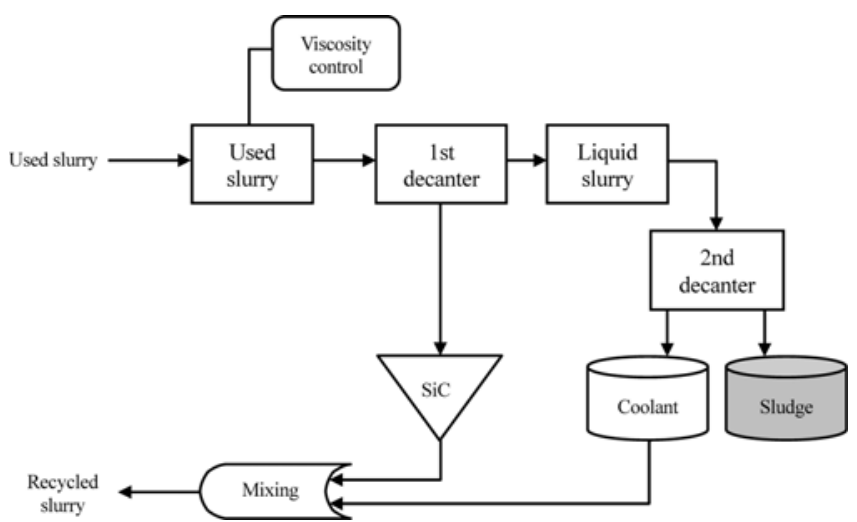

Fig. 1 Slurry recycling system 
25.2 million worth of material $(\$ 5 / \mathrm{kg})$. Accordingly, research has been actively conducted to recycle disposed $\mathrm{SiC}$ materials.

Wang et al. ${ }^{5}$ proposed a way of efficiently removing $\mathrm{SiC}$ through an Al-Si alloying process and Lin etc. ${ }^{6}$ used a centrifugation approach to separate silicon kerfs and silicon carbide abrasives. Wang et al. ${ }^{7}$ proposed a novel approach of directional solidification for separating submicron particles. Joyce and $\mathrm{Schmid}^{8}$ analyzed the impurities in silicon that were recovered from silicon kerf with pyrometallurgy. $\mathrm{Wu}$ and $\mathrm{Chen}^{9}$ found that $\mathrm{Si}$ and $\mathrm{SiC}$ could be separated by electrophoresis and gravitational settling. Meanwhile, Lin et al. ${ }^{10}$ successfully recovered $99.1 \mathrm{wt} \%$-pure $\mathrm{Si}$ by using a two stage phase-transfer separation process. Tsai ${ }^{11}$ suggested $\mathrm{Al}_{2} \mathrm{O}_{3}$ as abrasives instead of $\mathrm{SiC}$ and identified the possibility of separating $\mathrm{Si} / \mathrm{Al}_{2} \mathrm{O}_{3}$ mixtures with electrophoresis and gravitational settling. Yoko and Oshima ${ }^{12}$ proposed a new way of recovering Si from silicon sludge by using supercritical water in a semi-batch reactor.

The current drying method with a certain amount of Si-kerf to obtain $\mathrm{SiC}$ powder is limited to producing only low value-added slurry or fire-proofing material owing to low purity of SiC. High-purity $\mathrm{SiC}$ is thus required for the recycled powder to be used as a material for high value-added industries, such as structural materials or electronics parts. Kwon et al. ${ }^{13}$ developed a method to synthesize $\beta$, -SiC powder from the large amount of silicon sludge produced by the solar cell industry based on a direct carbonization synthesis method and additionally indicated the possibility of its use as a structural material or filtering material on the basis of SiC's characteristics, including high-temperature strength, wear-resistance, corrosion-resistance, and high thermal shock.

This study was aimed at developing a technology to economically mass produce recycled $\mathrm{SiC}$ powder, whose $\mathrm{SiC}$ content is equal to $99 \%$ of that of fresh $\mathrm{SiC}$, from solar silicon sludge. To that end, this study developed an approach of efficiently separating $\mathrm{Si}$ that condenses onto and remains in $\mathrm{SiC}$ particles even after the washing process. In addition, the recycled high-purity $\mathrm{SiC}$ powder was used to develop a porous $\mathrm{SiC}$ ceramic heat sink whose performance was verified through application to the cooling of the heat source of electronic goods.

\section{Experimental Methods}

\subsection{SiC Separation and Refinement Process}

Fig. 2 displays the $\mathrm{SiC}$ separation and refinement process. A large amount of Si fine powder and oil component of sludge can be removed through the first stage of the washing process, because the Si fine powder, whose size is $1 \mu \mathrm{m}$ and below, is very slow in terms of precipitation speed due to its smaller percentage compared to $\mathrm{SiC}$ particles. The sludge and additive water were mixed in a proportion of one to one (1:1) during the two iterations of washing. However, as it was difficult to remove $\mathrm{Si}$ condensed onto $\mathrm{SiC}$, an alkaline reagent of $\mathrm{KOH}$ or $\mathrm{NaOH}$ was added before 30 or 40 min -long agitation and the subsequent washing processes. In the second stage of filtration, applied to reduce the moisture of the washed slurry, proper size of filter pores is selected to additionally remove the remaining $\mathrm{Si}$ fine powder. In the third stage of drying, a microwave dryer to remove moisture in a short period of time was used.
The slurry used in the experiment was manufactured by mixing cooling oil(diethylene glycol) and $\mathrm{SiC}$ powder of Nanko ${ }^{1}$ in a weight ratio of one to one $(1: 1)$.

\subsection{Thermal Conductivity Measurement and Thermal Performance Experiment of Recycled SiC Heat Sink}

After manufacturing a Sic heat sink used for releasing heat of electronics with the recycled $\mathrm{SiC}$ powder, a laser flashing method ${ }^{2}$ was used to measure thermal conductivity. The laser flash method was originally developed to measure thermal diffusivity of solids. However, various methods have been proposed to measure the thermal diffusivity of many materials. Fig. 3 presents a schematic diagram of the thermal performance experiment. The experiments on thermal performance of aluminum and porous $\mathrm{SiC}$ heat sinks were conducted by using LED light as a heat source. A natural convection experiment was carried out without running a fan inside an acrylic box with the top open $(1 \mathrm{~m} \times 1 \mathrm{~m} \times 0.5 \mathrm{~m})$ and a forced convection experiment was conducted with the fan running.

\section{Results and Discussion}

\subsection{Precipitation Experiment}

Table 1 shows the variation of precipitation time according to additive water amount by using the slurry with a combination of $\mathrm{SiC}$ powder and diethylene glycol. The time required to reach $98 \% \mathrm{SiC}$ precipitation becomes shorter as the water content increases. In the case of the initial washing process where the slurry and water were mixed in a volume ratio of one to one (1:1) to approximate the conditions of Sample 4, the time taken to reach the precipitation level is about 4.5 hours. During the second washing process, most parts of the supernatant originating from the previous washing process were drained out and then the sludge was added by water in a ratio of one to one (1:1) to correspond to Samples 5 and 6 . In this case, about 3.5 hours are required to reach the precipitation level. During the following wash process, which was almost equal to Sample 6, with addition of $\mathrm{NaOH}$, precipitation was reached after approximately 2 hours.

Fig. 4 shows the results of the analysis of particle size of the

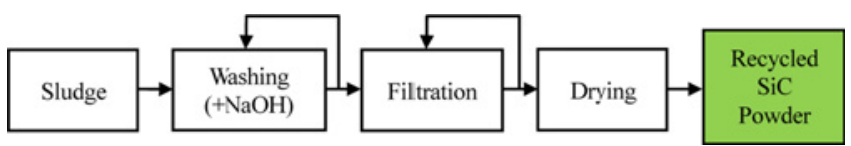

Fig. $2 \mathrm{SiC}$ separation and refinement process

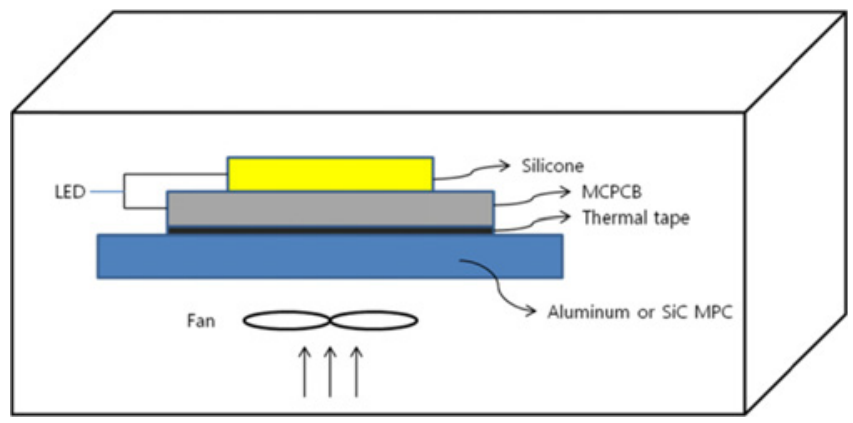

Fig. 3 Schematic of an apparatus for thermal performance experiment 
supernatant that was poured out after the second washing process. As seen in Fig. 4(a), the particle volume distribution is nearly normal with a range between $1 \mu \mathrm{m}$ and $10 \mu \mathrm{m}$ and the particle diameter corresponding to a cumulative value of $97 \%$ is about $10 \mu \mathrm{m}$. However, as seen in Fig. 4(b), the particle diameter corresponding to a cumulative value of $97 \%$ is about $4.4 \mu \mathrm{m}$ with respect to the particle number depending on the particle size, indicating that the particles inside the supernatant are mostly below $4.4 \mu \mathrm{m}$ in diameter. Also, it was found that particles of $1 \mu \mathrm{m}$ and below account for more than $70 \%$ of the total particles when they were counted. Therefore, Nanko's SiC powder, used in the experiment, has shown about $4.3 \mu \mathrm{m}$ of $\mathrm{D}_{6}, 10.1 \mu \mathrm{m}$ of $\mathrm{D}_{50}$

Table 1 Variations of SiC Precipitation percentage with additive water

\begin{tabular}{ccccccc}
\hline Sample no. & 1 & 2 & 3 & 4 & 5 & 6 \\
\hline Items & $15 \%$ & $30 \%$ & $45 \%$ & $60 \%$ & $75 \%$ & $90 \%$ \\
\hline Oiter content & $15 \%$ & $70 \%$ & $55 \%$ & $40 \%$ & $25 \%$ & $10 \%$ \\
\hline Density $(\mathrm{g} / \mathrm{ml})$ & 1.08 & 1.06 & 1.04 & 1.02 & 1.00 & 1.00 \\
\hline $\begin{array}{c}\text { Viscosity at } 25^{\circ} \mathrm{C} \\
\& \text { 100rpm(cp) }\end{array}$ & 27.0 & 17.4 & 11.1 & 8.5 & 6.9 & 3.9 \\
\hline $\begin{array}{c}\text { Reaching time for } 98 \% \\
\text { SiC precipitation(h) }\end{array}$ & 72 & 24 & 8.5 & 4.5 & 2.5 & 2.0 \\
\hline $\begin{array}{c}\text { SiC precipitation } \\
\text { percentage after } 8 \\
\text { hours(\%) }\end{array}$ & 63 & 93 & 97 & 98 & 99 & 100 \\
\hline
\end{tabular}

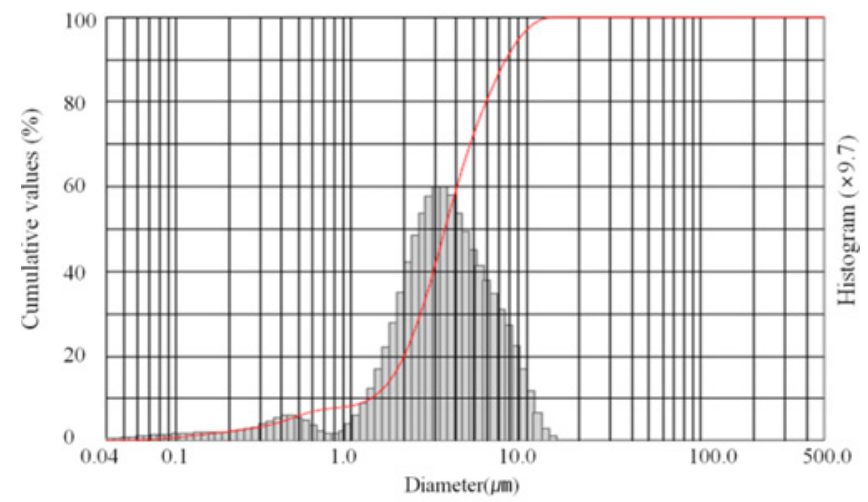

(a) Cumulative values and histogram of particle size distribution (in volume/undersize)

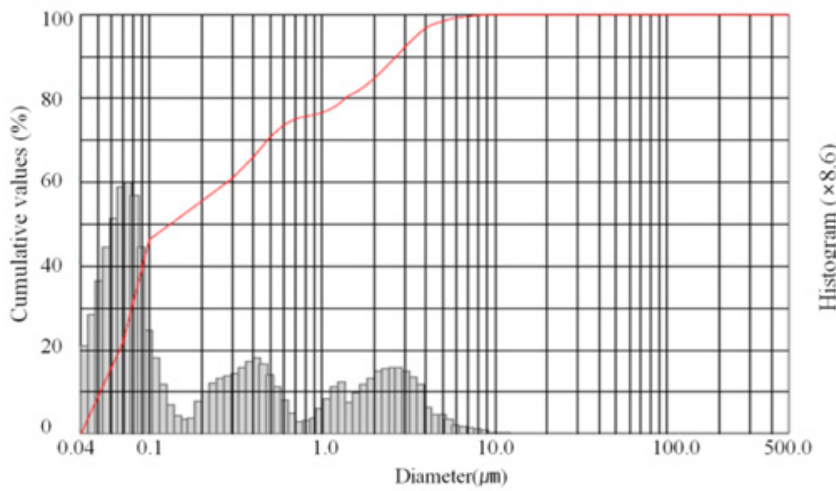

(b) Cumulative values and histogram of particle size distribution (in number/undersize)

Fig. 4 Distributions of particle size and number after washing with water and $21.2 \mu \mathrm{m}$ of $\mathrm{D}_{97}$, indicating that most parts of the Si fine powder were separated through the washing process. $\mathrm{D}_{6}, \mathrm{D}_{50}$, and $\mathrm{D}_{97}$ represent the $6 \%, 50 \%$ and $97 \%$ point in the cumulative undersize particle size distribution, respectively.

A simple washing process, however, is not sufficient to wash off submicron-sized Si fine powder that condenses onto and remains on the $\mathrm{SiC}$ particle surface inside the sludge. As illustrated in Fig. 5(a), for the slurry that is subjected to the washing process only, relatively smallsized $\mathrm{Si}$ particles adhere to relatively large-sized $\mathrm{SiC}$ particles. In order to remove these $\mathrm{Si}$ particles, $\mathrm{NaOH}$ is added in the final washing process. According to Fig. 5(b), after the addition of $\mathrm{NaOH}$, the Si fine powder is almost removed during the washing process.

\subsection{Filtration Process}

The washing is generally followed by filtration designed to reduce the moisture content of the sludge before the sludge goes through the drying process. Fig. 6 shows the sludge state of filtration with moisture of about between 40 and $50 \%$ and particle size of about $10 \mu \mathrm{m}$.

Meanwhile, out of the solid components of the sludge considered in this study, excluding the liquid components, $\mathrm{SiC}$ accounted for at least

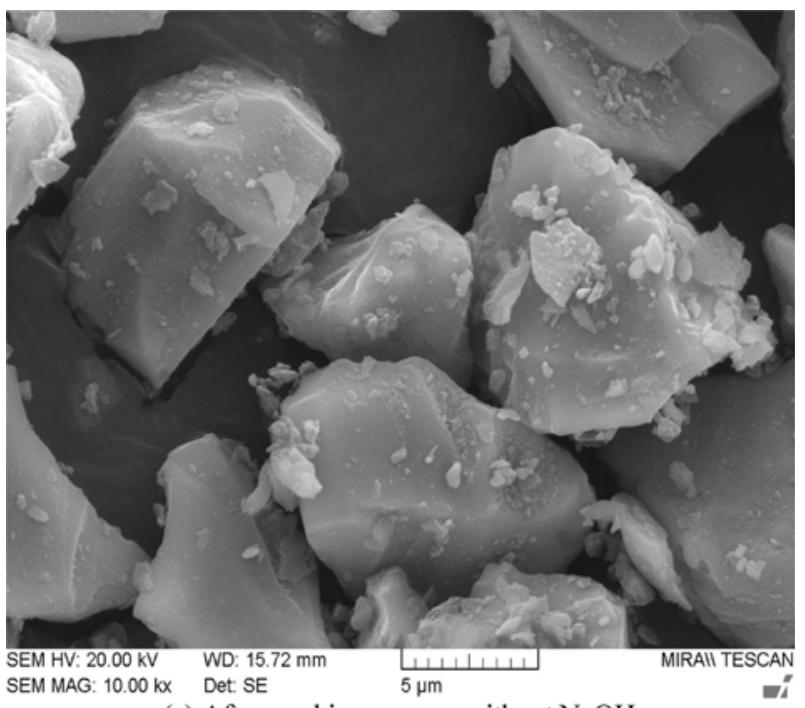

(a) After washing process without $\mathrm{NaOH}$

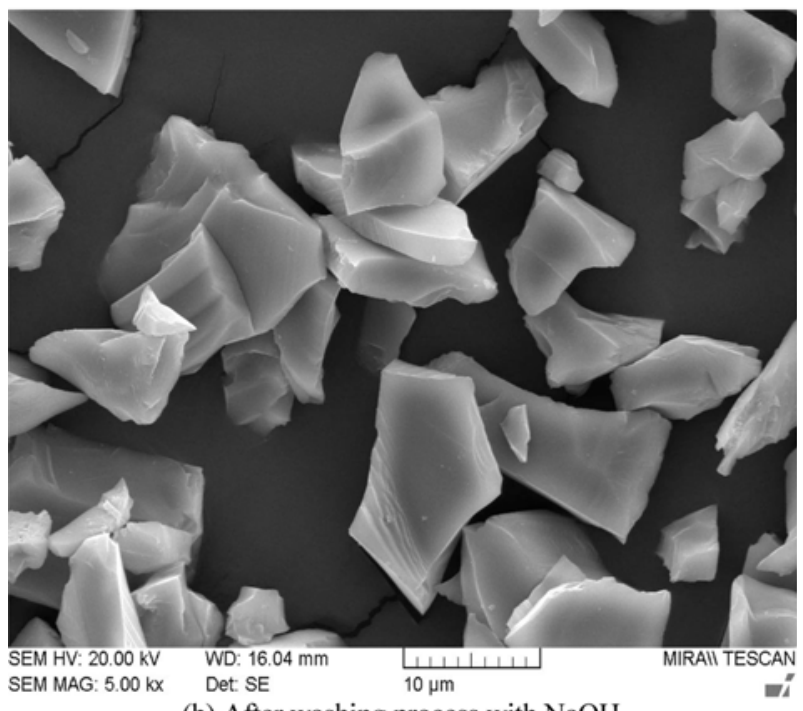

(b) After washing process with $\mathrm{NaOH}$

Fig. 5 SEM photograph of particle distributions 
$50 \%$ in terms of weight. Consequently, when passing through the filter, the sludge produced significant frictional heat caused by high pressure and, accordingly, the filter temperature reached almost $60^{\circ} \mathrm{C}$, nine or ten hours after the beginning of filtration. As it is generally desirable to use a membrane filter at a temperature of $70^{\circ} \mathrm{C}$ or below, the need for a cooling system was recognized. As a result, a water-cooled jacket was installed outside of the sludge tank with the aim of controlling the temperature rise, and the cooling system was operated when the sludge temperature reached $60^{\circ} \mathrm{C}$ Fig. 7 displays the variation of sludge temperature with time in the filtration apparatus equipped with the cooling system, indicating that the temperature of the sludge is controlled within a range of $60^{\circ} \mathrm{C} \pm 4^{\circ} \mathrm{C}$. Operating experiments were

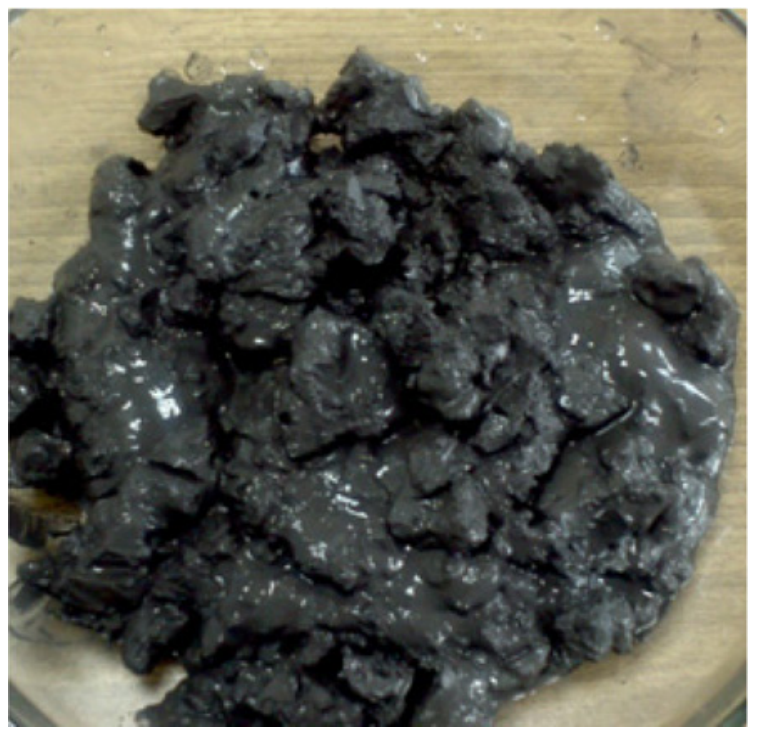

Fig. 6 Sludge after filtration

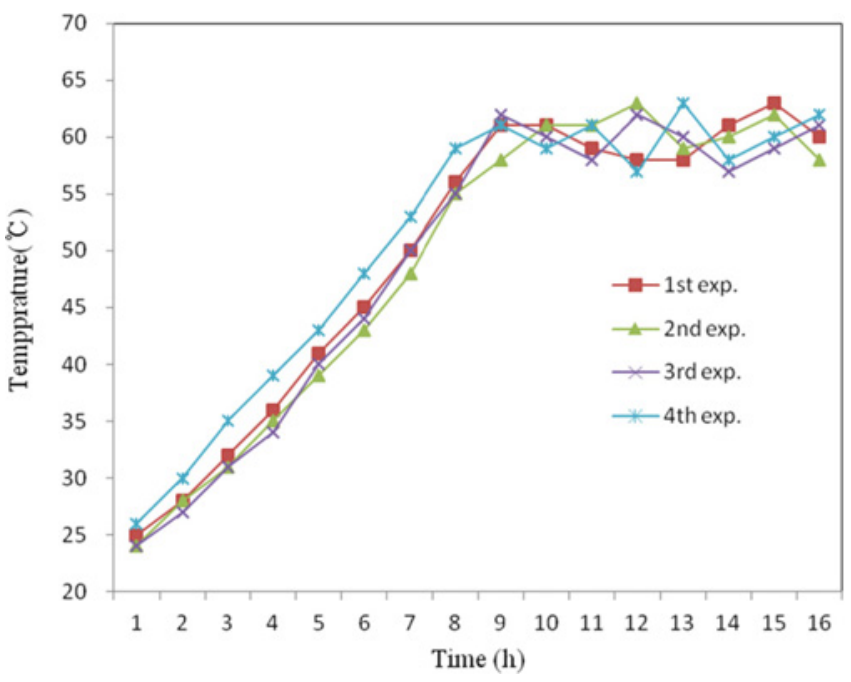

Fig. 7 Variation of sludge temperature with time

Table 2 Variation of powder characteristics with manufacturing method

\begin{tabular}{|c|c|c|c|c|}
\hline $\begin{array}{r}\text { Powder manufacturing } \\
\text { method }\end{array}$ & Drying only & Water washing and drying & $\begin{array}{l}\text { Water washing, water } \\
\text { washing with } \\
\mathrm{NaOH} \text { and drying }\end{array}$ & $\begin{array}{c}\text { Fresh SiC } \\
(\# 1500)\end{array}$ \\
\hline Powder color & Black & Light Brown & Light Green & Green \\
\hline $\mathrm{SiC}$ content $(\mathrm{wt} \%)$ & 74.9 & 97.1 & 98.5 & 99.3 \\
\hline Mean diameter $(\mu \mathrm{m})$ & 6.2 & 10.3 & 10.9 & 10.7 \\
\hline
\end{tabular}

performed four times over a period of two weeks in total to ensure stability of the experiment apparatus.

\subsection{Drying Process}

With regard to properties of the sludge passing through the filtration apparatus, it is combined with a fine powder having a mean size of $10 \mu \mathrm{m}$ and mainly water-containing liquid. A very small amount of liquid is mixed with the oil content that is not completely removed. Issues related to drying of the sludge used in this study included the following: (i) any increase in the amount of sludge to be dried caused a delay in drying the inside of the sludge, and (ii) the sludge formed into a mass after being dried. In order to resolve these issues, a microwave drying approach was adopted. Fig. 8 shows numerous pores resulted from the process of drying the sludge with the microwave. According to characteristics of the microwave drying, the sludge is heated at high temperature for a short period of time and its inside and outside regions are dried simultaneously while moisture escapes at a rapid pace, which consequently leads to the generation of those pores.

\subsection{Flushing Performance with Respect to the Water Inflow}

Table 2 describes the variation of the powder characteristics according to powder manufacturing methods to enhance the purity. The first powder that originates from the sludge is pulverized with its oil being removed after heat treatment at temperature of $270^{\circ} \mathrm{C}$ in an electric furnace without going through any process. The first powder is almost black in color, quite similar to that of the initial sludge, and the $\mathrm{SiC}$ content resulting from the crucible process amounts to $74.9 \mathrm{wt} \%$. The included Si fine powder contributes to lowering the mean value

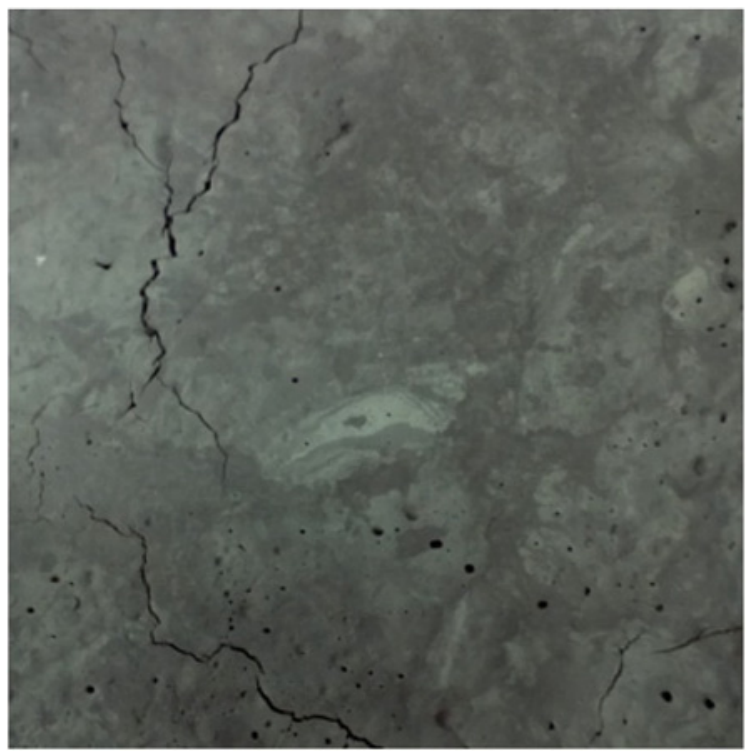

Fig. 8 Pores on the surface of the sludge after microwave drying 
and, as a result, the mean diameter of particles is $6.2 \mu \mathrm{m}$.

The second powder originates from drying the sludge after the washing process. The second powder is found to be light brown in color as the $\mathrm{Si}$ fine powder adhering to $\mathrm{SiC}$ remains even after the washing process. Its $\mathrm{SiC}$ content amounts to approximately $97.1 \mathrm{wt} \%$, indicating that a considerable amount of $\mathrm{Si}$ fine powder can be removed after going through just the washing step. Therefore, the mean diameter of particles is measured to be $10.3 \mu \mathrm{m}$, thus coming significantly closer to that of fresh $\mathrm{SiC}$.

Removal of a significant amount of Si fine powder that adhered to the surface of $\mathrm{SiC}$ by a reagent provides the main contribution for creating the light green color of the final drying powder, the original color of fresh SiC. The $\mathrm{SiC}$ content amounts to about $98.5 \mathrm{wt} \%$ and its mean diameter is $10.9 \mu \mathrm{m}$, even greater than that of the reference fresh Sic, $10.7 \mu \mathrm{m}$.

\subsection{Thermal Conductivity of SiC Heat Sink based on Multi- Modal Compositions}

As seen in Fig. 9, five samples $(40 \mathrm{~mm} \times 40 \mathrm{~mm} \times 2 \mathrm{~mm})$ were produced by adjusting amount of coarse powder and fine powder among the recycled $\mathrm{SiC}$ particles. The detailed compositions are shown
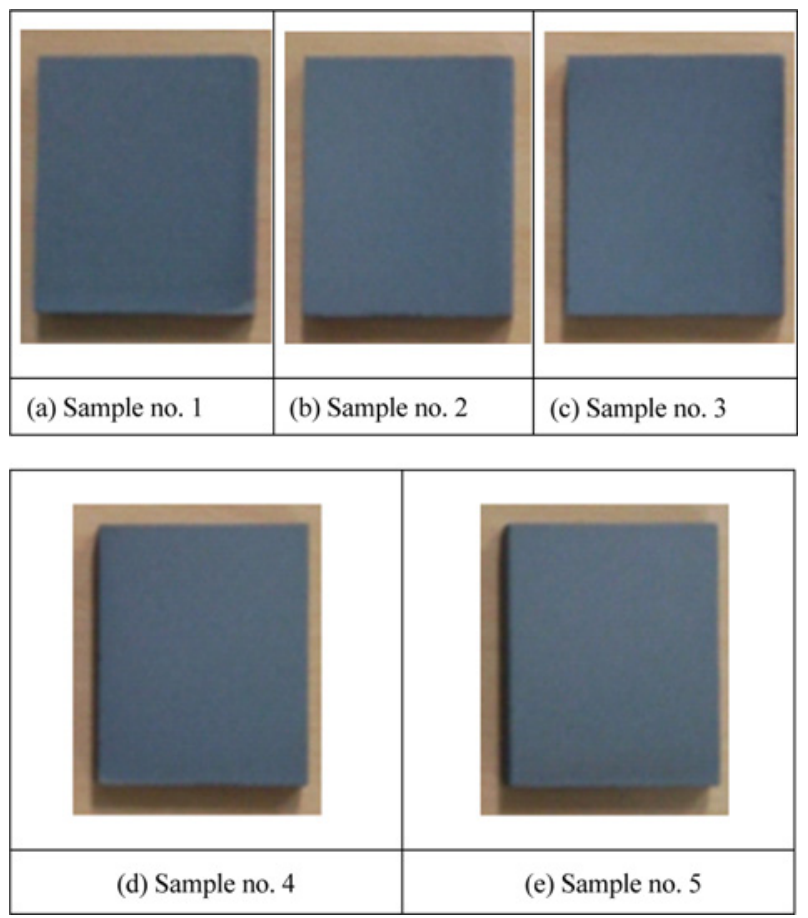

Fig. 9 Plate-type heatsinks with various compositions

Table 3 Multimodal compositions of the SiC samples

\begin{tabular}{cccccc}
\hline Sample No. & 1 & 2 & 3 & 4 & 5 \\
\hline $\begin{array}{c}\text { Composition } \\
\begin{array}{c}\text { Recycled SiC powder } \\
\text { (mean size: } 12.7 \mu \mathrm{m})\end{array}\end{array}$ & 80 & 78 & 76 & 74 & 72 \\
\hline $\begin{array}{c}\text { Recycled SiC } \\
\text { finer powder } \\
(\text { mean size:6.6 } \mu \mathrm{m})\end{array}$ & 10 & 12 & 14 & 16 & 18 \\
\hline $\mathrm{Li}_{2} \mathrm{CO}_{3}$ & 5 & 5 & 5 & 5 & 5 \\
\hline Metal-Glazing & 5 & 5 & 5 & 5 & 5 \\
\hline
\end{tabular}

in Table 3. The coarse powder and fine powder can be separated based on the precipitation speed in the washing process. Sintering temperature was intended to be capable of low temperature co-firing while the sample is held for two hours at temperature of $900^{\circ} \mathrm{C}$ In addition, the previously used carbonate was replaced with $\mathrm{Li}_{2} \mathrm{CO}_{3}$ with the aim of achieving firing at much lower temperature. According to the results of measuring the thermal conductivity of the ceramic heat sink with a laser flashing method, Sample 4 was found to have the highest thermal conductivity, about $10.3 \mathrm{~W} / \mathrm{mK}$ at room temperature, as seen in Table 4.

\subsection{Thermal Performance Experiment of Porous SiC Heat Sink}

A COB(chips on board) LED of approximately $1.5 \mathrm{~W}$ was used as a heat source and the thermal performance of the SiC heat sink was compared with that of an aluminum heat sink of the same size through experiments. Experimental conditions include ambient temperature of $25^{\circ} \mathrm{C}$, atmospheric pressure and natural convection without a cooling fan. According to Table 5, which shows the LED PCB temperatures at steady state, temperature of the porous $\mathrm{SiC}$ heat sink was $10^{\circ} \mathrm{C}$ lower than that of the same-sized aluminum heat sink, indicating better thermal performance. This is due to the fact that the heat transfer area of the porous $\mathrm{SiC}$ heat sink is much bigger than that of the aluminum heat sink. If micro pores can be modeled as a sphere with a diameter of $10 \mu \mathrm{m}$, the surface area of the SiC plate is larger than that of the aluminum plate about 300,000 times. Therefore, the porous $\mathrm{SiC}$ heat sink is better in terms of thermal performance and weight when natural convection cooling is necessary. On the other hand, under the condition of forced convection with a cooling fan, there is no difference between the porous $\mathrm{SiC}$ heat sink and the aluminum heat sink in terms of thermal performance, implying that the presence of numerous micro pores is effective only for natural convection.

\section{Conclusions}

In this study, a new process to get recycled pure $\mathrm{SiC}$ from solar sludge as well as porous $\mathrm{SiC}$ heat sinks as its application has been developed. Conclusions drawn from the study are as follows:

1) The solar sludge can efficiently remove Si particles adhering to $\mathrm{SiC}$ particles by going through the washing process alone, yielding

Table 4 Conductivity measurement of sample 4 with laser flash method

\begin{tabular}{ccccc}
\hline $\begin{array}{c}\text { Shot } \\
\text { number }\end{array}$ & $\begin{array}{c}\text { Ambient } \\
\text { temperature } \\
\left({ }^{\circ} \mathrm{C}\right)\end{array}$ & $\begin{array}{c}\text { Diffusivity } \\
\left(\mathrm{mm}^{2} / \mathrm{s}\right)\end{array}$ & $\begin{array}{c}\text { Conductivity } \\
(\mathrm{W} / \mathrm{mK})\end{array}$ & $\begin{array}{c}\text { Density } \\
\left(\mathrm{g} / \mathrm{cm}^{3}\right)\end{array}$ \\
\cline { 1 - 4 } 1 & 25.0 & 7.007 & 10.263 & \\
\cline { 1 - 4 } 2 & 25.1 & 7.020 & 10.282 & \multirow{2}{*}{1.917} \\
\cline { 1 - 4 } 3 & 25.1 & 7.020 & 10.281 & \\
\hline Mean & 25.1 & 7.016 & 10.275 & \\
\hline
\end{tabular}

Table 5 Variation of LED PCB temperature with heat sinks

\begin{tabular}{|c|c|c|}
\hline 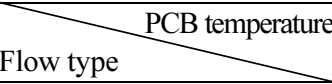 & $\begin{array}{c}\text { Aluminum heatsink } \\
\left({ }^{\circ} \mathrm{C}\right)\end{array}$ & $\begin{array}{c}\text { Porous } \mathrm{SiC} \text { heatsink } \\
\left({ }^{\circ} \mathrm{C}\right)\end{array}$ \\
\hline Natural convection & 78 & 68 \\
\hline Forced convection & 55 & 55 \\
\hline
\end{tabular}


roughly $97 \% \mathrm{SiC}$ powder. In particular, the addition of $\mathrm{NaOH}$ to the washing process contributes to obtaining recycled $\mathrm{SiC}$ powder with purity of $98.5 \%$ and particle diameter of about $10.9 \mu \mathrm{m}$.

2) During the filtration process, friction with the filter caused by $\mathrm{SiC}$ particles may damage the filter, thus necessitating a cooling system that keeps the filter at $70^{\circ} \mathrm{C}$ or below.

3) With regard to the solar sludge drying methods, it is found that microwave drying is capable of drying both the inside and outside of the sludge simultaneously at a rapid speed.

4) A porous $\mathrm{SiC}$ heat sink manufactured with recycled $\mathrm{SiC}$ can be used efficiently for releasing heat of electronic goods owing to its high thermal conductivity of $10 \mathrm{~W} / \mathrm{mK}$ and porosity of $30 \%$.

In the future, additional studies on the thermal performance of various shapes of recycled micro-pore $\mathrm{SiC}$ should be carried out.

\section{ACKNOWLEDGEMENT}

This work was supported by the Human Resources Development program(No. 20134030200230) of the Korea Institute of Energy Technology Evaluation and Planning(KETEP) grant funded by the Korea government Ministry of Trade, Industry and Energy.

\section{REFERENCES}

1. Mekhilef, S., Saidur, R., and Safari, A., "A Review on Solar Energy Use in Industries," Renewable and Sustainable Energy Reviews, Vol. 15, No. 4, pp. 1777-1790, 2011.

2. Möller, H. J., "Basic Mechanisms and Models of Multi-Wire Sawing," Advanced Engineering Materials, Vol. 6, No. 7, pp. 501513, 2004.

3. Bidiville, A., Wasmer, K., Michler, J., Nasch, P., Van der Meer, M., and Ballif, C., "Mechanisms of Wafer Sawing and Impact on Wafer Properties," Progress in Photovoltaics: Research and Applications, Vol. 18, No. 8, pp. 563-572, 2010.

4. Nasch, P. M. and Sumi, R., "Meeting Current and Future Wafering Challenges," Solid State Technology, Vol. 52, No. 3, pp. 32-36, 2009.

5. Wang, H., Tan, Y., Li, J., Li, Y., and Dong, W., "Removal of Silicon Carbide from Kerf Loss Slurry by Al-Si Alloying Process," Separation and Purification Technology, Vol. 89, pp. 91-93, 2012.

6. Lin, Y.-C., Wang, T.-Y., Lan, C.-W., and Tai, C. Y., "Recovery of Silicon Powder from Kerf Loss Slurry by Centrifugation," Powder Technology, Vol. 200, No. 3, pp. 216-223, 2010.

7. Wang, T., Lin, Y., Tai, C., Sivakumar, R., Rai, D., and Lan, C., “A Novel Approach for Recycling of Kerf Loss Silicon from Cutting Slurry Waste for Solar Cell Applications," Journal of Crystal Growth, Vol. 310, No. 15, pp. 3403-3406, 2008.

8. Joyce, D. B. and Schmid, F., "Recycling Fast-Sliced Silicon Swarf," Proc. of the $24^{\text {th }}$ EU PVSEC, 2009.
9. Wu, Y.-F. and Chen, Y.-M., "Separation of Silicon and Silicon Carbide using an Electrical Field," Separation and Purification Technology, Vol. 68, No. 1, pp. 70-74, 2009.

10. Lin, Y.-C. and Tai, C. Y., "Recovery of Silicon Powder from Kerfs Loss Slurry using Phase-Transfer Separation Method," Separation and Purification Technology, Vol. 74, No. 2, pp. 170-177, 2010.

11. Tsai, T.-H., "Silicon Sawing Waste Treatment by Electrophoresis and Gravitational Settling," Journal of Hazardous Materials, Vol. 189, No. 1, pp. 526-530, 2011.

12. Yoko, A. and Oshima, Y., "Recovery of Silicon from Silicon Sludge using Supercritical Water," Journal of Supercritical Fluids, Vol. 75, pp. 1-5, 2013.

13. Kwon, W. T., Kim, S. R., Kim, Y. H., Lee, Y. J., Jung, E. J., et al., "A Study on the Synthesis of SiC Powder from the Silicon Sludge of the Photovoltaic Industry," Materials Science Forum, Vol. 724, pp. 49-52, 2012. 